\title{
A Study on Adhesive Properties between GFRP Tube and Steel Tube
}

\author{
Mingqiao $\mathrm{ZHU}^{1}$, Yao $\mathrm{WANG}^{2}$, Ziwei $\mathrm{ZHANG}^{3}$ \\ Department of Civil Engineering \\ Hunan University of Science and Technology \\ Xiangtan, Hunan \\ e-mail: 1531290279@qq.com,547804542@qq.com, \\ 953129428@qq.com
}

\author{
Jiaoping LIU $^{4}$ \\ Department of Foreign Studies \\ Hunan University of Science and Technology \\ Xiangtan, Hunan \\ e-mail: 84554362@qq.com
}

\begin{abstract}
For the crucial issues of joints in the truss structure of pultruded GFRP tube, the double-sided shear adhesive test was performed on the steel tube joints and GFRP tube to explore the effect of different adhesive lengths on the distribution of adhesive stress, joint slip and bearing capacity, in order to provide the effective experimental basis and reference for the design of joint connection in the truss structure of GFRP tube.
\end{abstract}

Keywords-pultruded GFRP tube; adhesive length; adhesive connection; distribution of adhesive stress; joint slip

\section{INTRODUCTION}

The pultruded GFRP tube is the new composite tube that uses the glass fiber as the reinforcing material, the resin as the adhesive and glass fiber cloth as the wrapper. After being soaked completely and heated, formed and solidified in the metal mold, it can be finally achieved with the traction of tractor. Its high content of glass fiber leads to the outstanding physical and mechanical properties, which is suitable for the application in the situation with the high strength and large span. In the practical application, GFRP tube is generally connected with the metal parts in the structure. For the anisotropic GFRP tube, the connecting part is always the weakest section of structure. Compared with the mechanical connection, the adhesive one possesses the advantages of higher connection efficiency and high rigidity. Accordingly, the study on the adhesive properties of connection parts between GFRP tube and steel tube will be of critical significance.

The existing researches mainly focus on the lap connection of composite laminate, but not on the properties of adhesive connection between the new composite tube and metal parts. The adhesive property of adhesive connection is also related to the form of connection, the nature of bonded parts, the property of adhesive and the environment ${ }^{(1)}$. Zhang Entian $^{(2)}$ et al. Studied the change law of adhesive strength of graphite/polyimide composite laminates with the connection type and lap length. The results indicated that the strength of double lap connection was significantly higher than that of single lap connection. For the lap connection, when the lap length reached to the certain value, the increase in the loading capacity was lowered. Gunnion ${ }^{(3)}$ et al. built the parametric finite element model for the scarfed lap joint of composite laminate to study the effect of different parameters on the stress distribution in the adhesive layer; Guo $\mathrm{Xia}^{(4)}$ et al. built the finite element model for the tensile strength of single lap joint of composite laminate to analyze the effect of lap length on the stress distribution and failure mode. The objective of this study is to study the law of adhesive stress between the stainless steel tube connection part and GFRP tube with the change in the loading and then achieve the design values of effective adhesive length, rigidity and joint load, in order to provide the basis and reference for the further design of joint connection in the truss structure of GFRP tube.

\section{EXPERIMENT}

\section{A. Experimental Materials and Properties}

The adhesive is the structural adhesive DP460 of 3M, with the curing time of 24 hours. The internal and external stainless steel casting is connected with the bolt using the threaded connection to form the metal joint. As shown in Fig.1, S1 and S2 are the critical points of two adhesive ends respectively and the length between $\mathrm{S} 1$ and $\mathrm{S} 2$ is the adhesive length. 3-6 pieces of resistance stress gauge are placed along the direction of adhesive length according to the practical situation. The properties of GFRP tube and stainless steel tube are shown as follows. $10^{5}$

TABLE I. EXPERIMENTAL MATERIALS

\begin{tabular}{ccccc}
\hline Material & $\begin{array}{c}\text { Diameter } \\
(\mathbf{m m})\end{array}$ & $\begin{array}{c}\text { Thickness } \\
(\mathbf{m m})\end{array}$ & $\begin{array}{c}\text { Tensile } \\
\text { Modulus of } \\
\text { Elasticity (E) }\end{array}$ & $\begin{array}{c}\text { Tensile } \\
\text { Strength } \\
(\mathbf{M P a})\end{array}$ \\
\hline GFRP tube & 42 & 5 & $2.6 \times 10^{4}$ & 440 \\
\hline $\begin{array}{c}\text { External } \\
\text { Stainless } \\
\text { Steel Tube }\end{array}$ & 50 & 4 & $1.93 \times 10^{5}$ & $\geq 520$ \\
\hline $\begin{array}{c}\text { Internal } \\
\text { Stainless } \\
\text { Steel Tube }\end{array}$ & 32 & 4 & $1.93 \times 10^{5}$ & $\geq 520$ \\
\hline
\end{tabular}

\section{B. Experimental Objective and Measures}

To study the adhesive performance between GFRP tube and stainless steel, the adhesive length was selected as the variable from the influencing factors on the adhesive strength. The specimen group was set to explore the relationship between the adhesive length and the average shear strength and the ultimate bearing capacity, the law for the adhesive strength of different adhesive lengths with the change in the loading, and the load-displacement curve for different adhesive lengths. Specimens were divided into five groups, with three same components in each group. The specimen parameters were shown in Table 2 and the components in 
Fig.2. According to the objective of this study, the following measurements were performed:

(1) Joint displacement under different levels of load.

(2) Maximum load value for the failure of joint.

(3) Stress of steel tube at the adhesive segment under different levels of load.

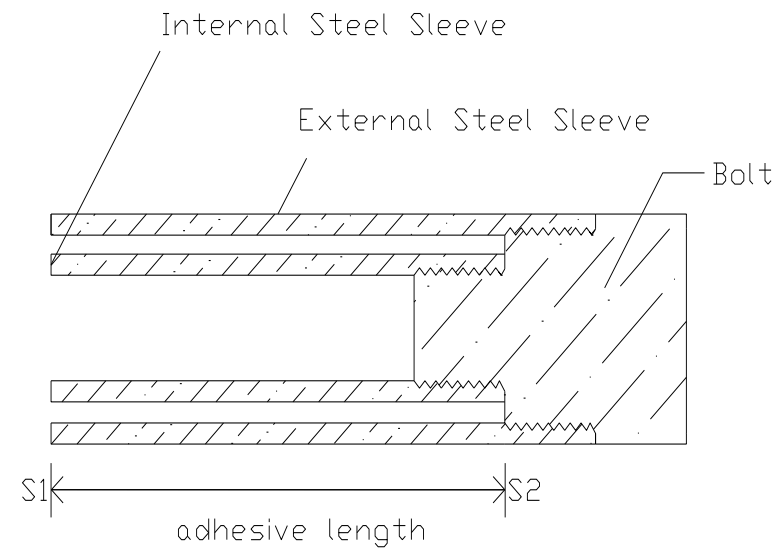

Figure 1. Cross Section of Metal Joint.

TABLE II. SPECIMEN PARAMETERS

\begin{tabular}{ccccc}
\hline $\begin{array}{c}\text { Specime } \\
\text { n No. }\end{array}$ & $\begin{array}{c}\text { Adhesive } \\
\text { Length } \\
(\mathbf{m m})\end{array}$ & $\begin{array}{c}\text { Adhesive } \\
\text { Area } \\
\left(\mathbf{m m}^{2}\right)\end{array}$ & $\begin{array}{c}\text { Adhesive } \\
\text { Thickness } \\
(\mathbf{m m})\end{array}$ & $\begin{array}{c}\text { Curing } \\
\text { Time } \\
\text { (Day) }\end{array}$ \\
\hline $1 \#$ & 34 & 7812 & 0.2 & 1 \\
$2 \#$ & 68 & 15625 & 0.2 & 1 \\
$3 \#$ & 102 & 23437 & 0.2 & 1 \\
$4 \#$ & 136 & 31250 & 0.2 & 1 \\
$5 \#$ & 150 & 34687 & 0.2 & 1 \\
\hline
\end{tabular}

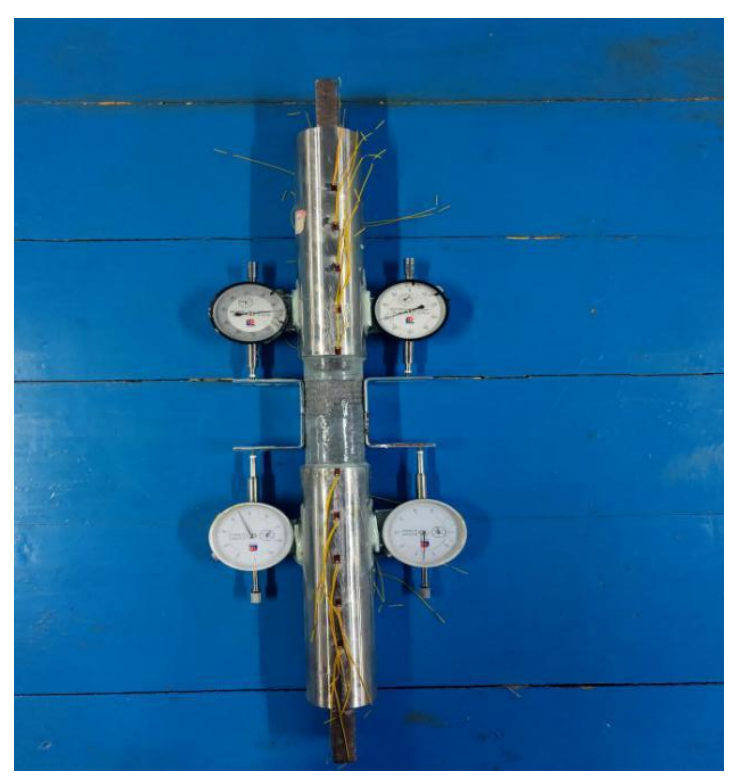

Figure 2. Physical View of Component.

\section{RESULTS AND ANALYSIS}

\section{A. Distribution Curve for the Stress of Steel Tube and Adhesive Layer along the Adhesive Length}

According to the stress measured from the experiment, the distribution diagram of stress under different levels of load was drawn as follows. Afterwards, the average adhesive stress $\tau$ at different positions along the length could be calculated according to the following equation of static equilibrium (as follows) and then the smooth curve was used to connect the points of adhesive stress and achieve the adhesive stress curve along the adhesive length. Where, Es is the elasticity modulus of stainless steel tube. Referring to Manual for Physical Properties of Metals, the value of Es is $1.93 \times 105$. As is the cross-sectional area of external steel sleeve, $\mathrm{d}$ is the diameter of adhesive disc and hi is the distance between two measuring points of strain.

$$
\begin{aligned}
& \tau_{i}=\frac{\left(\varepsilon_{i+1}-\varepsilon_{i}\right) E_{s} A_{s}}{\pi d h_{i}} \\
& =\frac{\left(\varepsilon_{i+1}-\varepsilon_{i}\right) \times 1.93 \times 10^{5} \times 577.26}{3.14 \times 42 \times h_{i}} \\
& =\frac{0.84479\left(\varepsilon_{i+1}-\varepsilon_{i}\right)}{h_{i}}
\end{aligned}
$$

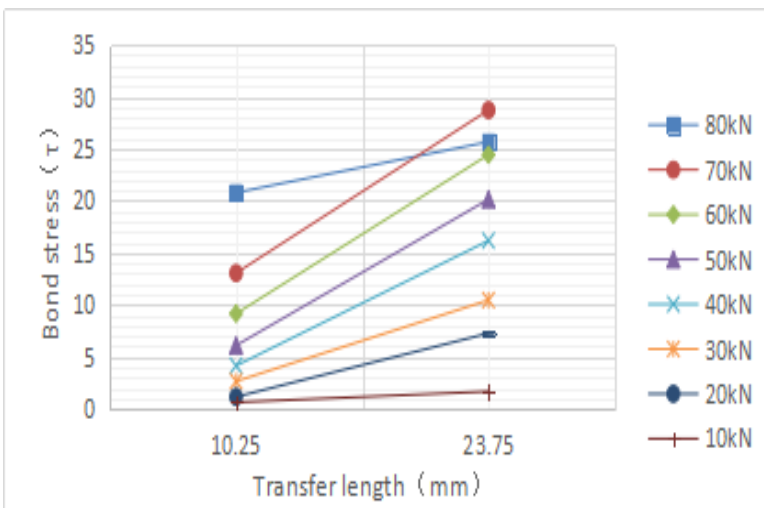

Figure 3. Diagram for Distribution of $34 \mathrm{~mm}$ Adhesive Stress.

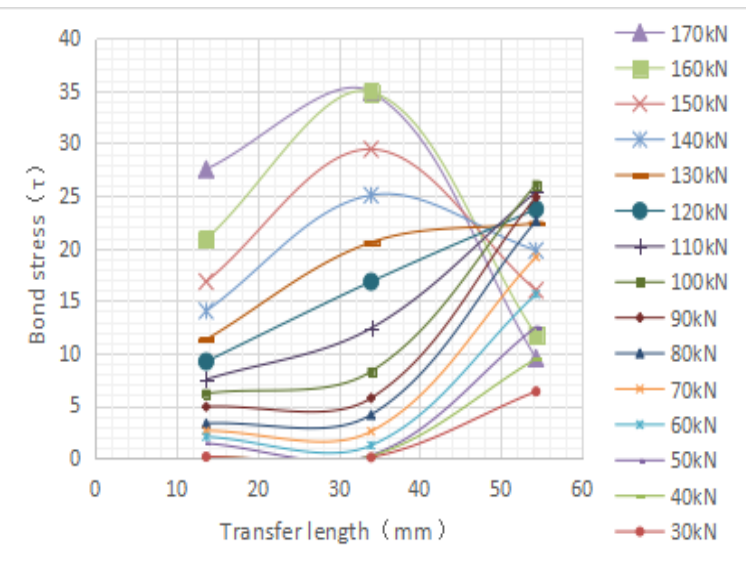

Figure 4. Diagram for Distribution of $68 \mathrm{~mm}$ Adhesive Stress. 


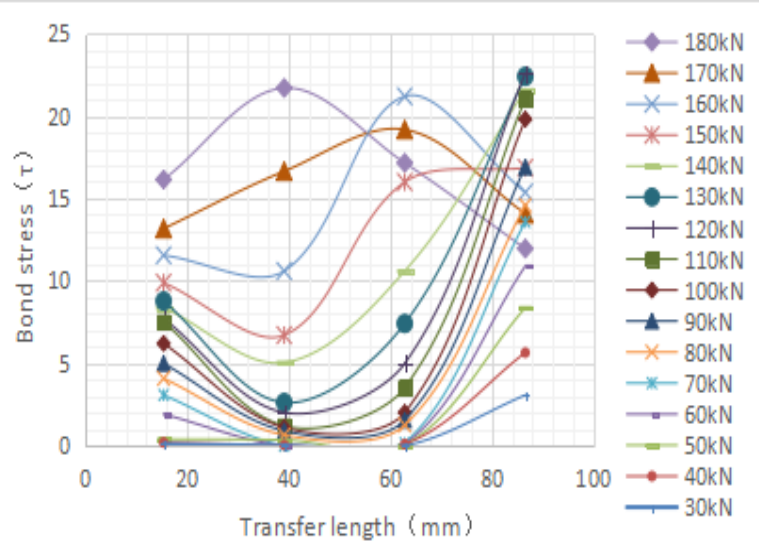

Figure 5. Diagram for Distribution of $102 \mathrm{~mm}$ Adhesive Stress.

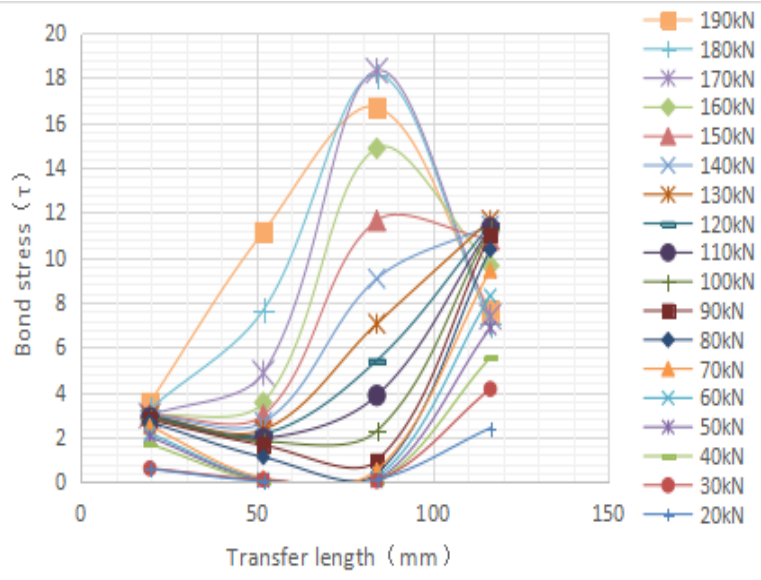

Figure 6. Diagram for Distribution of $136 \mathrm{~mm}$ Adhesive Stress.

\section{B. Distribution Law of Adhesive Stress along the Adhesive Length}

According to the distribution curve of adhesive stress along the adhesive length, its distribution law can be achieved as follows:

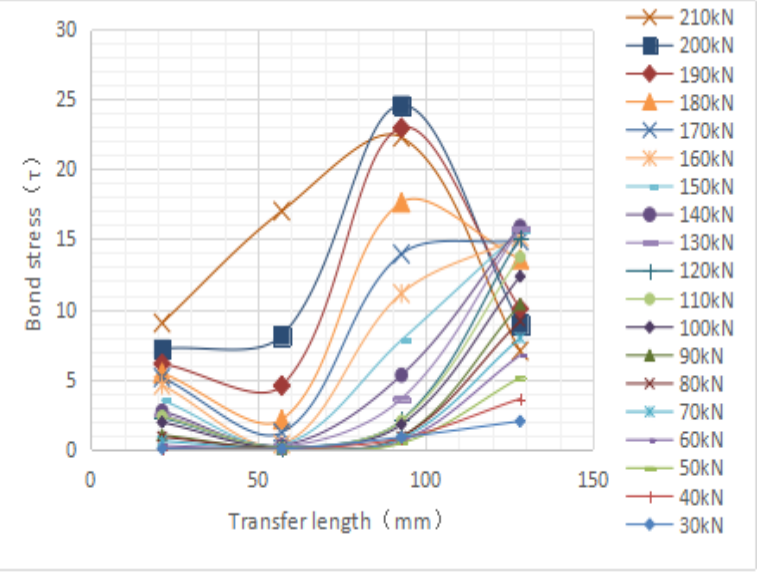

Figure 7. Diagram for Distribution of $150 \mathrm{~mm}$ Adhesive Stress.

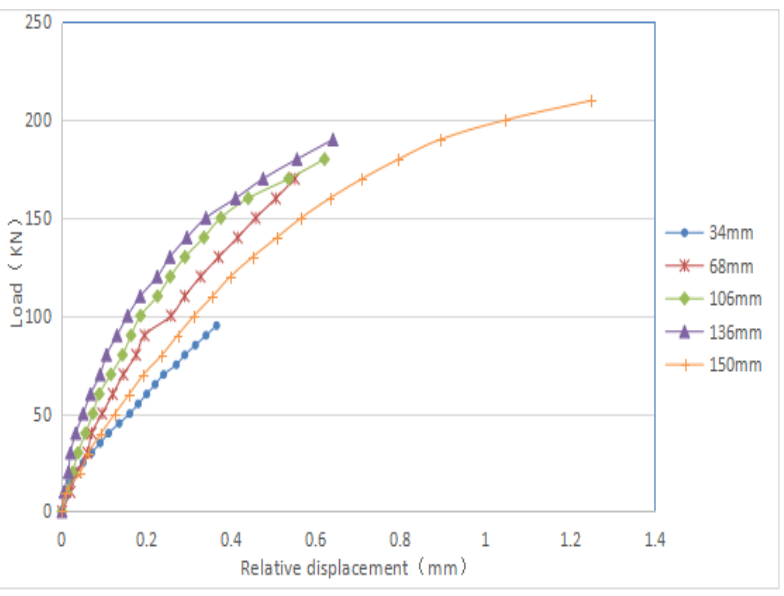

Figure 8. Joint Load Displacement Curve.

(1) Laws for the distribution of adhesive stress under the different adhesive lengths are basically the same. In the beginning of loading, the adhesive stress is not evenly distributed along the adhesive length, but is mainly centralized at ends of S1 and S2. Where, the adhesive stress is extremely low in the central segment, but highest at the end of S1.

(2) With the increase in the load, the adhesive stress at the end of S1 becomes the first to reach to the peak and then it slows, where the adhesive layer begins the phase of plastic yielding. When the load reaches to the certain value, the adhesive stress at the end of S1 becomes to be decreased. The adhesive stress will then be transferred to the neighboring area towards $\mathrm{S} 2$ and the internal force is redistributed.

(3) When the load keeps increasing and the adhesive stress at the joint reaches to the peak, the adhesive layer will begin to be yielded, the adhesive stress is then decreased and the adhesive stress is transferred to the area towards S2. When the joint is destroyed, the peak point of adhesive stress will appear in the middle segment of joint.

\section{Node Load Displacement Curve}

According to the load displacement curve of this study, when the adhesive length is $34 \mathrm{~mm}$ and $68 \mathrm{~mm}$, the load displacement shows the good linear relationship from the loading to the failure of joint and the specimen belongs to the obvious brittle failure. When the adhesive length is $106 \mathrm{~mm}$, $136 \mathrm{~mm}$ and $150 \mathrm{~mm}$, the specimen shows the certain linear relationship in the beginning of loading, but when it gets close to the failure load, the displacement of each node becomes larger. The load displacement curve shows the distinct gentle slope in the later period of loading. It indicates that in the beginning of loading, the adhesive layer works within the elastic range. When the load keeps increasing, the adhesive layer at the end of S1 experiences the elastic failure at first. Afterwards, the node displacement becomes larger and the middle adhesive layer beings to bear the adhesive stress. If the adhesive length is short, the duration for the middle adhesive layer to bear the adhesive stress will also be short and thus the failure becomes rapid. If the adhesive length is long, the adhesive stress will be gradually 
transferred from $\mathrm{S} 1$ to $\mathrm{S} 2$, leading to the relatively long period of failure and the certain ductility. In the strict sense, the adhesive connection is not the brittle failure exactly.

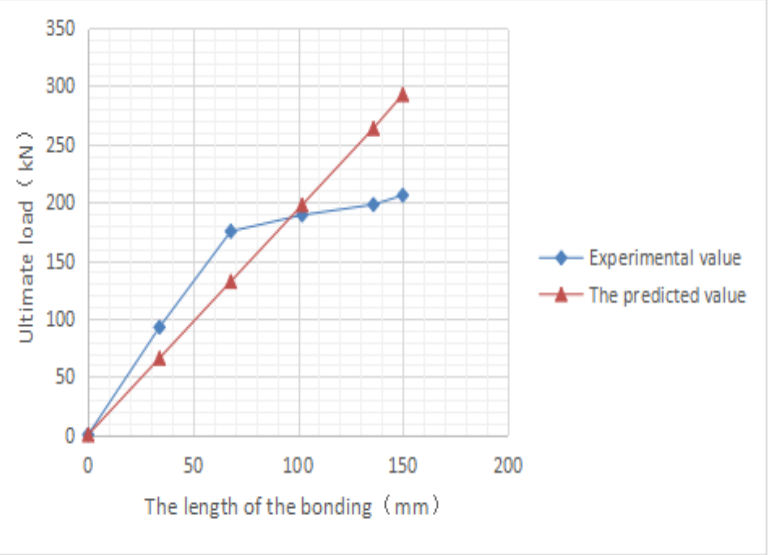

Figure 9. Curve of Adhesive Length and Limit Load.

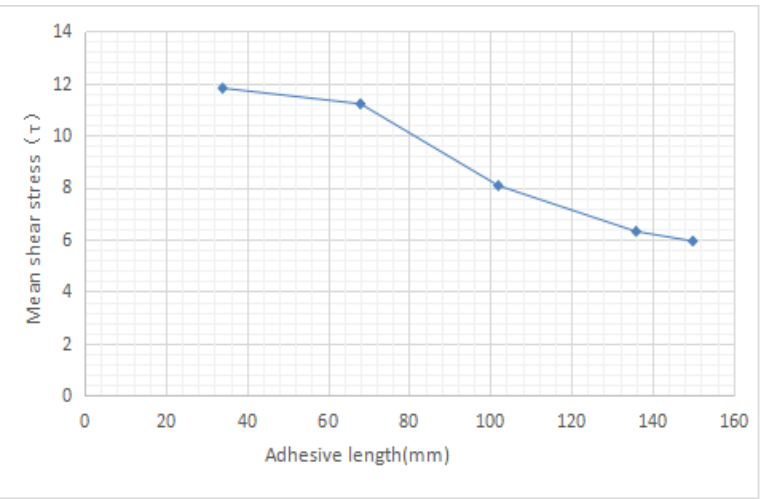

Figure 10. Curve of Adhesive Length and Average Shear Strength.

\section{Relationship between the Adhesive Length and Limit Load and Average Shear Strength}

In the figure of relationship between the adhesive length and limit load, the predicted value is the theoretical load value that is calculated based on the average shear strength of single lap GFRP plate, while the experimental value is the practical load value that is achieved from the adhesive test of GFRP tube. According to the above figure, the predicted load value is linearly increased with the adhesive length. For the experimental load value, it is gradually increased with the length in the earlier stage; but when the length reaches to $68 \mathrm{~mm}$, the increase in load becomes slower, indicating no linear relationship between the limit load and adhesive length. Accordingly, the predicted value cannot predict the adhesive strength of GFRP tube well, but it can predict the limit load value within the range of $0-100 \mathrm{~mm}$ conservatively. According to the figure of relationship between the average shear strength and adhesive length, the average shear strength at $34 \mathrm{~mm}$ is highest, as the adhesive length with the highest utilization rate. But $34 \mathrm{~mm}$ is a bit short and the limit load value is small, which is not suitable for the engineering. Therefore, $68 \mathrm{~mm}$ will be the optimum adhesive length for the connection between GFRP tube and metal parts.

\section{E. Failure Modes with Different Adhesive Lengths}

The failure reason of specimen in each group is the fracture of fiber wire on the surface of GFRP tube and there is the separation failure between layers. It is because the lateral (along the direction of thickness) strength of GFRP tube is low and its tensile strength is lower than that of adhesive. Hart Smith once made suggestions in the adhesive connection of composite laminates that the direction of outermost ply should be parallel to the one of loading, in order to avoid the interlaminar failure. Considering the shear strength of mechanical connection materials, the outer layer of GFRP tube in this study is wrapped by the glass fiber. The direction of outermost layer is not exactly parallel to the one of loading, which is also the main reason for the mode of node failure

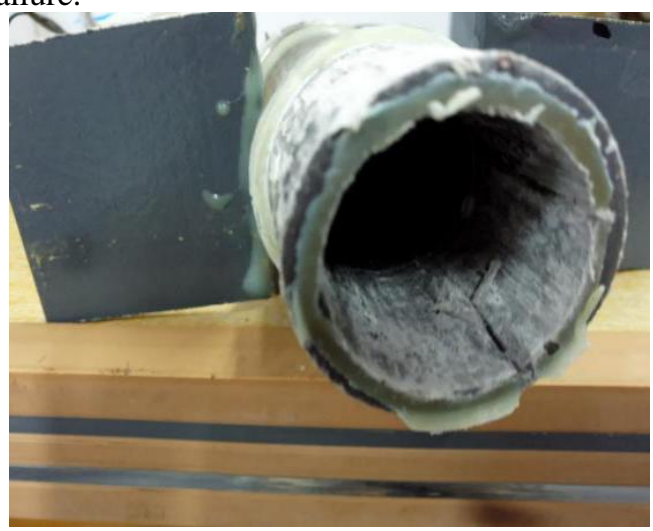

Figure 11. Failure with $34 \mathrm{~mm}$ Adhesive Length.

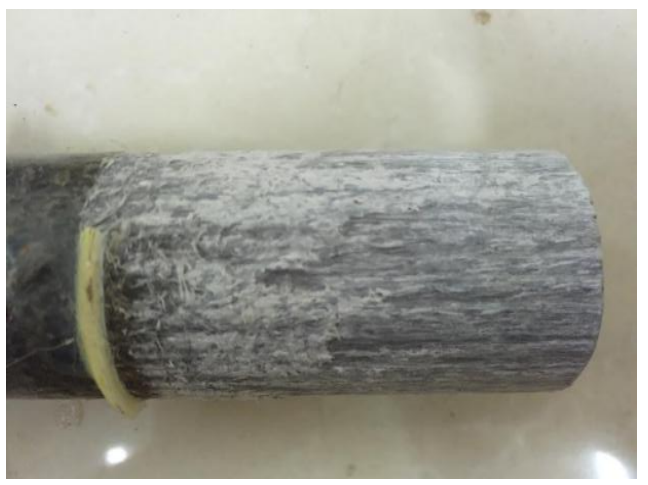

Figure 12. Failure with $68 \mathrm{~mm}$ Adhesive Length.

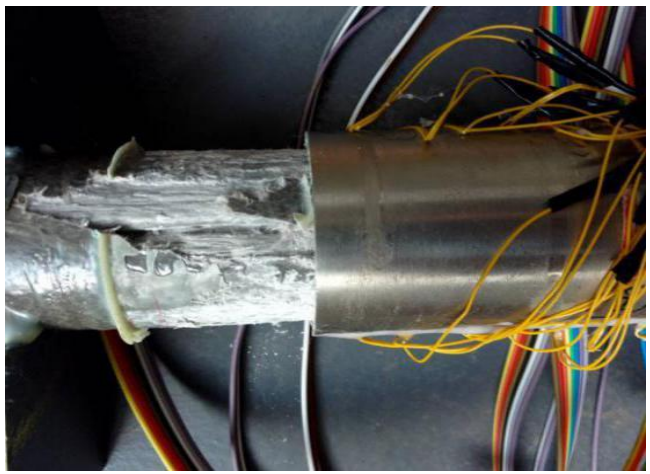

Figure 13. Failure with $102 \mathrm{~mm}$ Adhesive Length. 


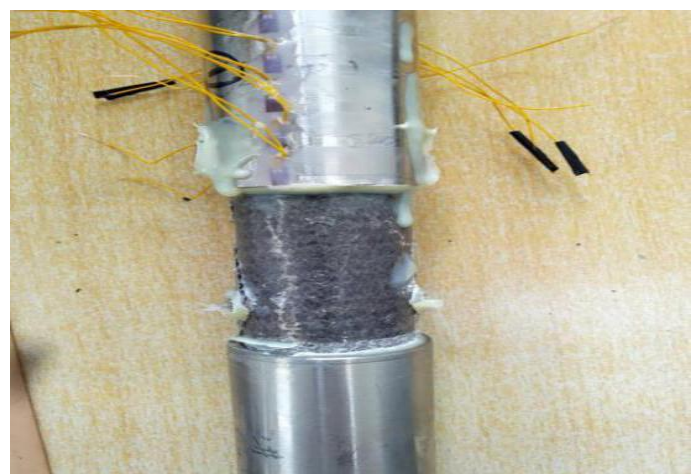

Figure 14. Failure with $136 \mathrm{~mm}$ Adhesive Length.

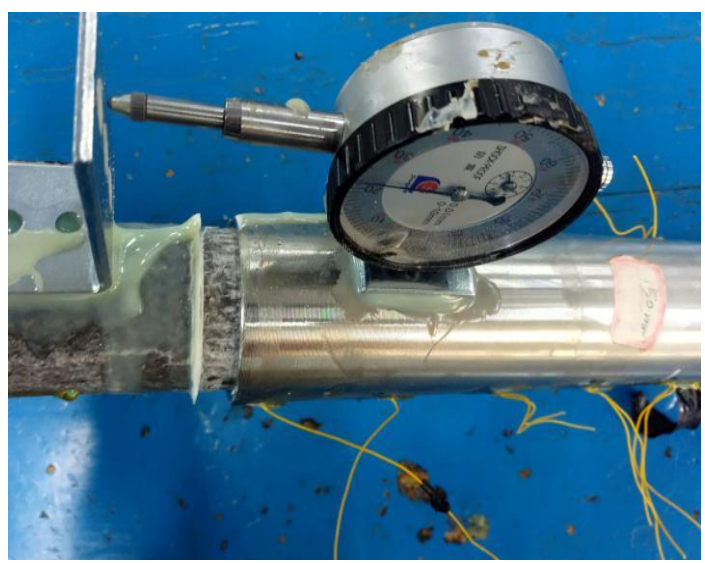

Figure 15. Failure with 150mm Adhesive Length.

\section{CONCLUSION}

(1) Several conclusions can be drawn according to the analysis on the adhesive stress curve of different adhesive lengths obtained from the experiment: the distribution of adhesive stress is not uniform along the adhesive length; within the elastic range, the stress is mainly centralized at the end of S1 and the adhesive stress of middle adhesive layer is extremely low; with the increase in the load, the adhesive layer at the end of S1 is firstly yielded and then the middle adhesive layer begins to bear the force; the selection of design load for nodes with different adhesive lengths can be referred to the load value at the time that the adhesive layer begins to be yielded.

(2) The adhesive connection between GFRP tube and metal parts does not belong to the brittle failure exactly. When the adhesive length is short, the load displacement is basically the linear relationship; when the adhesive length is long, the load displacement curve will show the obvious slope in the middle and late stages. The failure at the longer adhesive length will lead to the better ductility.

(3) There is not the linear relationship between the bearing capacity of GFRP tube and metal parts and the adhesive length. With the increase in the adhesive length, when the adhesive length is over $68 \mathrm{~mm}$, the average shear strength will be reduced gradually. $68 \mathrm{~mm}$ is the effective adhesive length for the adhesive connection between GFRP tube and metal parts.

(4) The failure modes for the adhesive between GFRP tube and metal parts are all the interlaminar separation failure, which indicates that the interlaminar adhesive strength of GFRP tube is weaker than the adhesive strength between the adhesive and GFRP tube. The enhanced adhesive strength and improved adhesive interface between the adhesive and GFRP tube will not improve the adhesive strength.

\section{ACKNOWLEGEMENT}

This work was supported by The National Natural Science Fund(Grant No. 51578236).

\section{REFERENCES}

[1] Xie Mingjiu. Joints for Composites Materials [M]. Shanghai Jiao Tong University Press, 2016.

[2] Zhang Entian, Qu Chunyan, Chen Weijun. Development and Application of Structural Adhesives [J]. Materials China, 2009,28:910

[3] Gunnion A J, Herszberg I. Parametric study of scarf joints in composite structures[J]. Composite Structures, 2006,75: 364-376.

[4] Guo Xia, Guan Zhidong, Liu Sui. Effect of Lap Length on the Adhesive-bonded Single-lap Composite Joints [J]. Science \& Technology Review, 2013,31-[7] 